\title{
Research on fillet Simulation machining of spiral bevel gear based on five-axis machining center
}

\author{
TANG Qingchun, WANG Yutao, ZHOU Zexi \\ Engineering Training Center,GuangXi University of Science and \\ Technology, LiuZhou, GuangXi, 545006
}

Keywords: Fillet machining; Automatic programming; Precision detection; Simulation machining

\begin{abstract}
The traditional spiral bevel gear fillet processing process mainly rely on artificial grinding method, resulting in low efficiency processing, work intensity, parts quality can not guarantee such problems. Aiming at the above problems, a method of fillet machining in five - axis machining center is proposed. The feasibility of the method is verified by UG automatic programming, simulation machining, precision detection and Simulation machining of five axis machining center in VERICUT.
\end{abstract}

\section{Introduction}

Spiral bevel gear is an important part of mechanical transmission, is the curved teeth, relative to the straight bevel gear, bevel gear , with a large coefficient of overlap, high carrying capacity, more stable operation, the transmission process of small noise etc[1] .It Is widely used in automobiles, ships, aerospace, machine tools, and agricultural machinery and other fields. For the spiral bevel gear processing methods have been a lot of research at domestic and foreign research, as the bevel gear technology is difficult, only American Gleason, Swiss Oerlikon and Germany Klingelnberg three companies have this technology and the bevel gear machining system, they represent the bevel gear three Kind of system, the system, each other is not open. But in the domestic development of NC gear machine has made some progress, the development of China's Qinchuan machine factory and Xi'an Jiao Tong University developed YH2240 CNC spiral bevel gear milling machine, with the five axis CNC controller to achieve free form processing, can processing all kinds of gear tooth surface of space, than the traditional bevel gear milling machine machining precision improve the level 1, reached level 6. Zhongnan University Hualili Precision Machinery Co., Ltd. developed five-axis linkage YK2045 CNC spiral bevel gear grinding machine, so that China's CNC machine tool technology in the processing accuracy and grinding efficiency reached the international advanced level.

Although the special spiral bevel gear CNC machining technology has become more mature, but for the domestic foreign special machine tool system is expensive and spiral bevel gear fillet processing technology research is very small. In view of these problems, this paper proposes a spiral bevel gear fillet machining method based on five-axis machining center, and uses UG software to program the spiral bevel gear. Firstly, the CLS cutter file is generated by the UG precision detection, simulation processing without interference and collision. Secondly, after a special post-processing to get NC program. Finally in the VERICUT five-axis machining center for simulation processing. The method ensures that there is no interference or no collision in the process. The tool path is in accordance with the design of the spiral bevel gear, and the feasibility and correctness of the method are verified.

\section{Spiral bevel gear UG automatic programming}

UG automatic programming process is the use of completed graphics model for interactive programming process. The user only needs to determine the cutting tool, the cutting depth, the 
cutting area, the cutting method, the cutting mode, the cutting boundary, the cutting depth and the cutting speed according to the process flow of the craft card, and you can automatically generate roughing and finishing tool trajectory in UG. When the user through the simulation process to confirm the tool path is correct, and no interference and collision, you can output tool file (CLSF) program, this process for the UG CNC machining automatic programming process. Unified set finishing allowance of $0 \mathrm{~mm}$, the following is a spiral bevel gear tool path NC programming scheme:

1 overall contour cavity milling (three-axis rough 、 semi-finishing)

Cutting area: in addition to the gear surface at the bottom of the gear part; cutting sequence: depth first; machining allowance: $0.5 \mathrm{~mm}$; cutting mode: following parts.

2 tooth top surface of fixed axis contour milling (three axis finishing)

Cutting area: tooth surface; cutting mode: reciprocating; driving method: surface drive; projection vector: towards the driver.

3 gear top fillet variable shaft profile milling (finishing)

Cutting area: the top of the gear two corners; cutting mode: reciprocating; drive method: surface drive; projection vector: towards the driver.

4 Tooth outer fillet of fixed axis contour milling v variable axis contour milling (finishing)

Fixed axis contour milling cutting area: the top of the gear outside the fillet and tooth profile concave convex outside the fillet; cutting mode: reciprocating; drive method: surface drive; projection vector: towards the driver.

Variable axis contour milling cutting area: tooth profile convex surface outside the fillet; cutting mode: reciprocating; driving method: surface drive; projection vector: towards the driver

5 tooth profile concave convex surface of fixed axis contour milling v cavity milling (finishing)

Concave cutting area: tooth profile concave; cutting mode: reciprocating; driving method: surface drive; projection vector: towards the driver.

Convex cutting area: tooth profile convex; cutting sequence: layer priority; cutting mode: reciprocating.

The following are the corresponding CNC machining toolpath map:

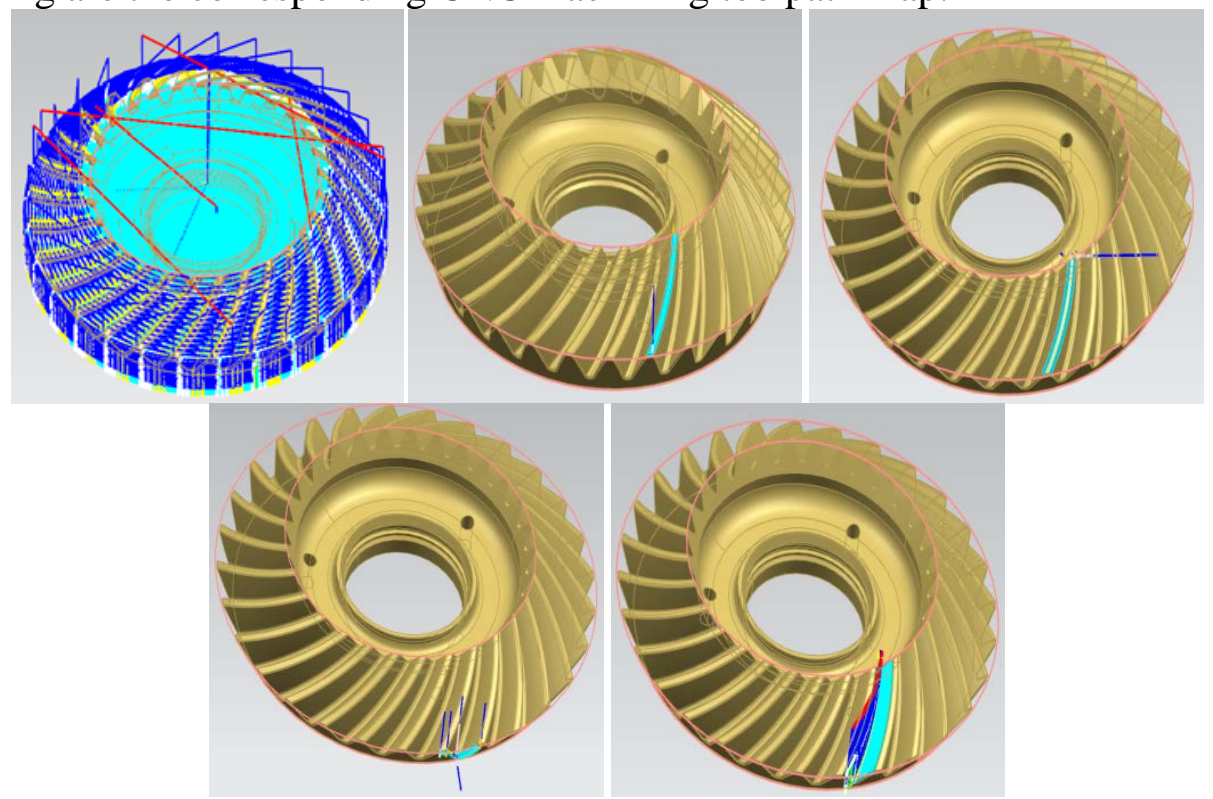

Fig. 1 NC machining tool path of spiral bevel gear

\section{UG simulation machining and precision detection}

\section{1. UG simulation machining ${ }^{[7]}$}

After the completion of a machining operation, the UG simulation machining function is used to check whether the tool path is correct, whether there is interference or collision and so on. The 
process inspection in two ways: Replay and Dynamic, in the manner of Replay can clearly see the tool path, and dynamic cutting; In the Dynamic mode, we can see the dynamic process of the workpiece defined by the cutting tool. After the end of the tool path, we can see the shape of the machined part. When all operations have been completed, simulated machining is performed. Figure 6 shows setting up collision detection function before simulation machining. Figure 7 is the spiral bevel gear with Dynamic mode under the tooth, tooth profile, fillet after processing the shape of parts. The shape of the part is exactly the same as that of the part design. Therefore, the tool path is consistent with the programming trajectory.

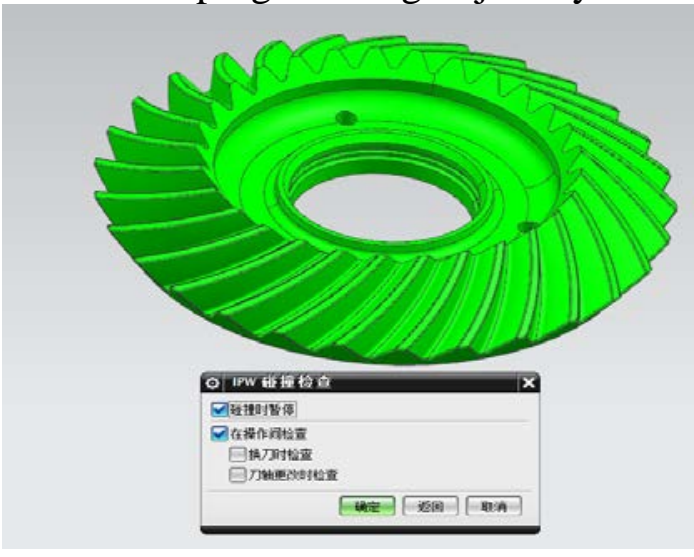

Fig. 2 Collision detection

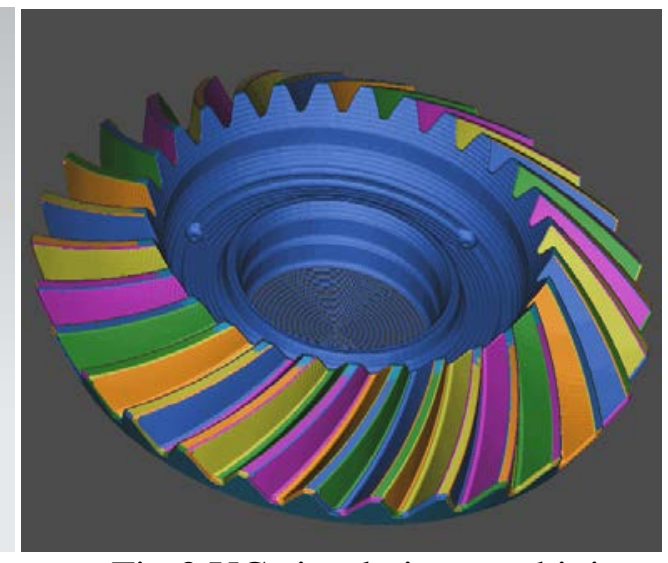

Fig.3 UG simulation machining

\section{2. Detection of gear shaping precision}

In order to further confirm the feasibility of the programming trajectory, the 3D dynamic module of UG is loaded to detect the machining precision. Therefore, the machining accuracy of the workpiece is checked by random point detection. By randomly extracting the top gear tooth fillet, tooth outer fillet point distance to inspect, the machining allowance was $0.006602 \mathrm{~mm}$, $-0.005195 \mathrm{~mm}$, and the roughness value is in accordance with the processing technology requirements.
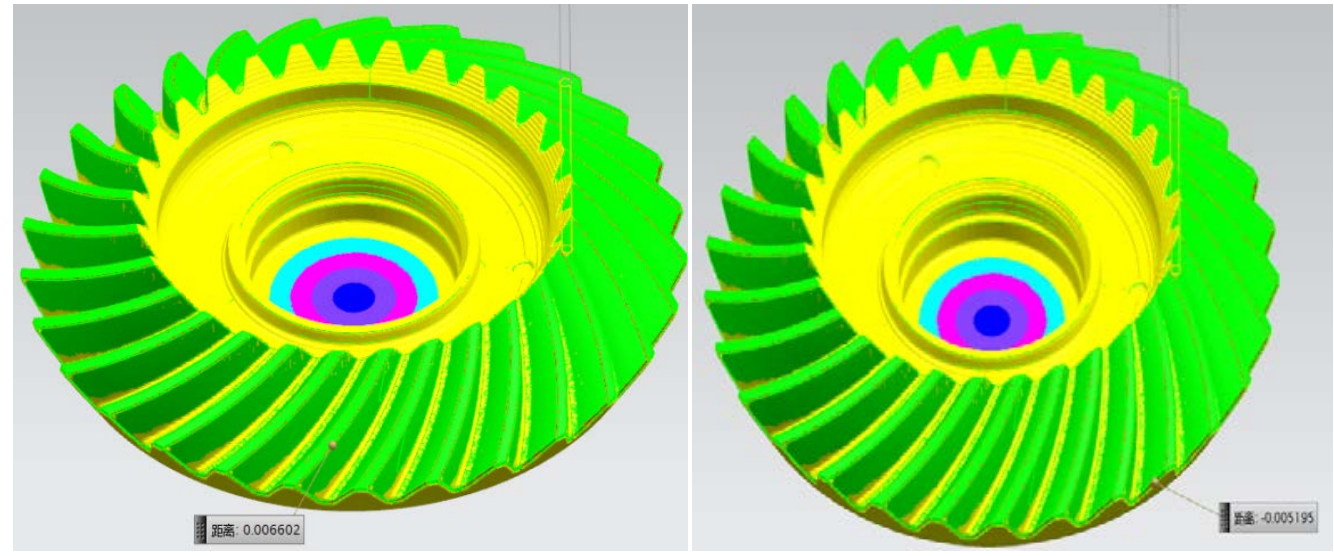

Fig. 4 (a) Detection of the fillet point of the gear top Fig. 4 (b) Tooth outer fillet detection

\section{VERICUT five axis machining center simulation $G$ code}

In this paper, the BV100 five-axis high-speed vertical milling machining center is used to simulate the spiral bevel gear ${ }^{[3]}$. The UG program is used to generate the tool file (CLSF), and the NC program is recognized by special post-processing. NC program into the VERICUT simulation process, get the following Figure4, Figure 5 and Figure6. As the actual processing only need a group of gears can be the corresponding processing program, the other gears machining can be adjusted by the rotation angle of the machine, so VERICUT simulation of a set of gear data. Figure 4 is the simulation of rough after the spiral bevel gear shape, and no interference during processing and other collisions, Compare the shape of the part design, the two contours match, verify the 
correctness of the rough track. Figure 5 is the tooth top surface, tooth top concave fillet simulation processing partial magnification diagram. It can be seen from the figure, the top surface of the tooth surface after processing smooth, tooth top concave fillet tool processing transition smooth, the formation of the surface smooth, and the surface trajectory consistent with the design trajectory. Figure 6 is a partially enlarged view of the tooth outer fillet machining, which is consistent with the design trajectory and fillet contour is clear and smooth. According to the five-axis high-speed vertical milling machining center for spiral bevel gears and fillet, we can see that this paper proposes the feasibility of fillet machining of spiral bevel gears based on five-axis machining center.



Fig. 5 Parts drawing after rough machining

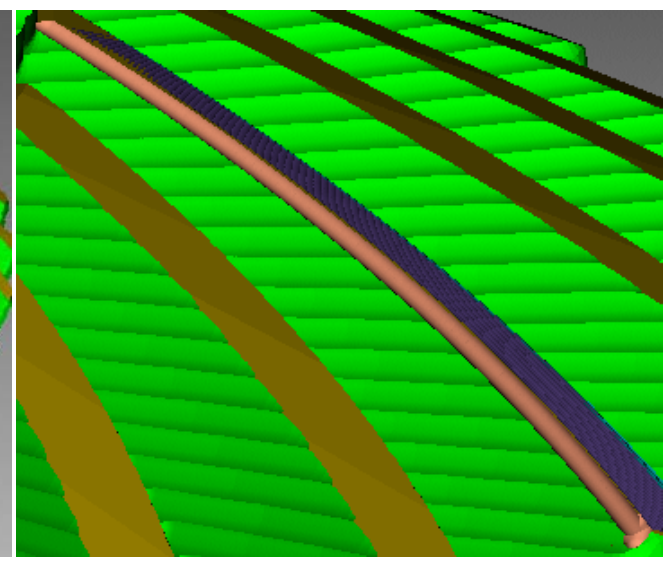

Fig. 6 Concave fillet machining enlarged view

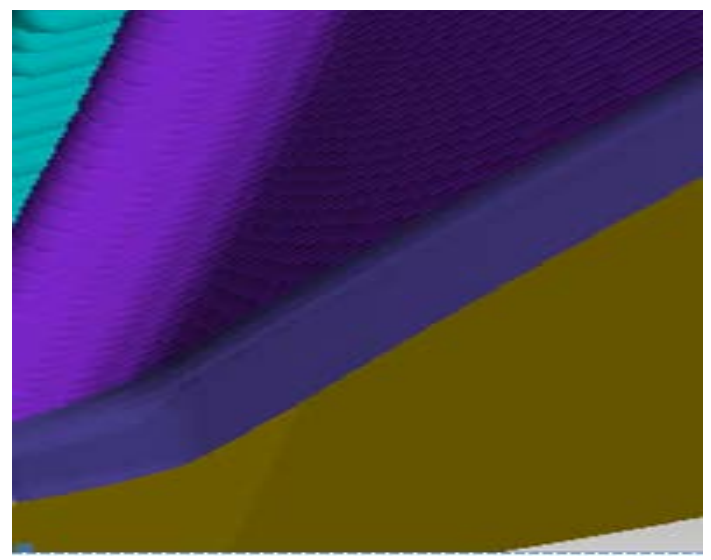

Fig. 7 Tooth outer fillet machining enlarged view

\section{Conclusions}

According to the method of machining the fillet in the five-axis machining center, firstly the UG CAM function is used to realize the automatic programming of the spiral bevel gear NC machining. Secondly, UG simulation processing and machining allowance precision detection are used to meet the requirements. Finally, application of post-processing NC program in VERICUT simulation processing. It can be seen from the above, through the UG automatic programming, simulation processing, precision detection and VERICUT five-axis machining center simulation processing, the fillet whole machining process with smooth surface, no interference and collision problems, verified the feasibility and correctness of the method of five axis machining center of spiral bevel gear of the fillet, Which provides a theoretical reference for improving the precision of parts, reducing the labor intensity and improving the working efficiency in actual work.

\section{References}

[1] LIN Zhiwei. Automatic NC Programming of Gleason Spriral Bevel Gear's Profile Processing on UG[J]. Journal of Minnan Normal University（Nat. Sci. ）,2015.28（03）:42-46, 
[2] Han Weina. Research on the method of addendum lines' chamfering for Driven gear in spiral bevel gear pair [D]. Tianjin University,2007.

[3] TANG Qing-chun, LIU Qian, MA Zhong-liang, ZHANG Jian. The Application Research of VE R ICUT Simulation Software in Five Axis Machining [J]. Modular Machine Tool \& Automatic Manufacturing Technique,2014,(09):131-133+136.

[4] XIONG Yue-dong, WANG Tai-yong, ZHANG Wei. Research on NC machining 3D simulation of spiral bevel and hypoid gears [J]. Manufacturing Automation,2005,(06):21-23.

[5] LI Qiang, YAN Huan, YAN Hong-bo, LI Li. The proposed of high-tooth logarithmic spiral bevel gear process route [J]. Manufacturing Automation,2014,36(20):60-63.

[6] W AN G Yanzho ng Z HOU Yunfei LI Zuozhang W ANG Chenpei L I Xiaoqing L I Bin. NC Machining of Bevel Gear Tooth Surface Based on a Five - axis Numerical Control Machine [J]. China Mechanical Engineering,2001 (08):63-66+5.

[7] Liu Kai Xia Jiqiang Shi Kan. Simulation Processing of Elliptic Bevel Gear based on UG [J]. Journal of Mechanical Transmission,2012,36(08):112-115+118. 